\title{
Common Variants Associated to Type 2 Diabetes in the Italian Population
}

\author{
Sara Bonetti ${ }^{*}$, Chiara Zusi ${ }^{*}$, Elisabetta Rinaldi ${ }^{1}$, Maria Linda Boselli1, Cristina Patuzzo ${ }^{2}$, \\ Elisabetta Trabetti ${ }^{2}$, Giovanni Malerba ${ }^{2}$, Cristina Bianchi ${ }^{3}$, Gianmarco Lombardi 4 , \\ Gianluigi Zaza ${ }^{4}$, Stefano Del Prato ${ }^{3}$, Giovanni Gambaro4, Enzo Bonora1, \\ Riccardo C. Bonadonna ${ }^{5,6}$, Maddalena Trombetta ${ }^{1 \#}$
}

\author{
${ }^{1}$ Division of Endocrinology, Diabetes and Metabolism, Department of Medicine, University and Hospital Trust of Verona, \\ Verona, Italy \\ ${ }^{2}$ Department of Neuroscience, Biomedicine and Movement Sciences, Section of Biology and Genetics, University of Verona, \\ Verona, Italy \\ ${ }^{3}$ Section of Diabetes and Metabolic Disease, Department of Clinical and Experimental Medicine, University of Pisa and Azienda \\ Ospedaliero-Universitaria Pisana, Pisa, Italy \\ ${ }^{4}$ Renal Unit, Department of Medicine, University-Hospital of Verona, Italy \\ ${ }^{5}$ Department of Medicine and Surgery, University of Parma, Parma, Italy \\ ${ }^{6}$ Division of Endocrinology and Metabolic Diseases, Azienda Ospedaliero-Universitaria di Parma, Parma, Italy \\ Email: "maddalena.trombetta@univr.it
}

How to cite this paper: Bonetti, S., Zusi C., Rinaldi, E., Boselli, M.L., Patuzzo, C., Trabetti, E., Malerba, G., Bianchi, C., Lombardi, G., Zaza, G., Del Prato, S., Gambaro, G., Bonora, E., Bonadonna, R.C. and Trombetta, M. (2021) Common Variants Associated to Type 2 Diabetes in the Italian Population. Open Journal of Endocrine and Metabolic Diseases, 11, 24-42. https://doi.org/10.4236/ojemd.2021.111003

Received: November 4, 2020

Accepted: January 19, 2021

Published: January 22, 2021

Copyright (c) 2021 by author(s) and Scientific Research Publishing Inc. This work is licensed under the Creative Commons Attribution International License (CC BY 4.0).

http://creativecommons.org/licenses/by/4.0/

\begin{abstract}
Genome-wide association studies have identified numerous genetic variants for type 2 diabetes (T2D). Most genetic loci discovered to date were studied in Caucasians or Asian ancestry, however, there are no data regarding a quite large Italian sample. Therefore, we investigated T2D genetic susceptibility of 143 single nucleotide polymorphisms (SNPs) within 30 genes involved in glucose metabolism in a large Italian case-control study. For the study, 1875 Caucasian patients were selected from three Italian cohorts. Age, gender, BMI and fasting plasma glucose (FPG) values were collected. Population was split in cases and controls based on FPG values or T2D diagnosis. T2D subjects and whom with FPG higher that $126 \mathrm{mg} / \mathrm{dL}$ were recruited as cases whereas subjects with normal values of FPG were considered controls. In each subject 143 SNPs were genotyped. To evaluate the association between genetic variations and diabetes status, a logistic regression analysis, adjusted for age, sex and BMI, was performed. Overall, 948 (50.6\%) had T2D. Twenty out of 143 variants within 11 different genes resulted significantly associated to T2D. Four of them were located into TCF7L2 gene and presented the highest odd ratio (from 1.42 to 1.57). At least two SNPs were located within $K C N J 11$, WFS1, $A B C C 8$, $J A Z F 1$ and $H N F 1 B$ genes and one SNP each was identified in ADAMTS9,
\end{abstract}

*These authors contributed equally to this manuscript. 
IGF2BP2, FTO, G6PC2 and GCK genes. Our findings support the role of 11 genes involved in glucose homeostasis in T2D risk development in a large Italian population. We found that such genetic information may be advantageous for predicting T2D.

\section{Keywords}

T2D, Genetics, Susceptibility, SNPs, Variants

\section{Introduction}

Type 2 diabetes (T2D) is a worldwide disease and it is expected to affect more than 629 million people by 2045 [1]. Type 2 diabetes is a complex disease, characterized by the interplay between environmental and genetic factors, and it is mainly determined by impaired beta cell function and/or insulin sensitivity [2]

In the past years, many studies have been conducted in order to unravel the genetic background of type 2 diabetes. Before 2007, candidate and linkage approaches lead to identify a small number of associated loci (PPARG, KCNJ11, CAPN10, WFS1, IRS1 and TCF7L2) [3] [4]. From 2007 to present day, the advent of high-throughput genotyping technology, such as Genome Wide Association (GWA) Scan, increased the number of T2D associated loci, identified in different ethnic groups, up to over 240 genetic risk loci with about 400 independent association signals [5] [6] [7]. Initially, the first GWA studies lead to replicate the already known associated SNPs and to identify at least six novel T2D loci (CDKN2A/2B, IGF2BP2, CDKAL1, HEEX, SLC30A8) [8] [9] [10] [11]. The number of candidate polymorphisms further increased in the following years as a result of other GWA and meta-analysis studies that added KCNQ1, CDC123, CAMK1, JAZF1, THADA, TSPAN8, ADAMTS9, NOTCH2/ ADAM3O to the list [12] [13] [14] [15]. In 2010, Voight and collaborators discovered other T2D associated loci (ARAP1, BCL11A, ZBED3, KLF14, TP53INP1, CHCHD9, CENTD2ARAP1, HMGA2, ZFAND6, PRC1, TLE4 and DUSP9) and interestingly, among them, there were also two MODY genes (HNF1A and $H N F 4 A$ ) [16]. Previously published papers already reported an effect of SNPs located into MODY genes (HNF4A, PDX1, NEUROD1, KLF11, GCK, CEL) on type 2 diabetes, suggesting an influence of these monogenic diabetes loci also on the common form of the disease [17] [18] [19] [20]. Subsequent studies expanded their investigation to the genetic background of type 2 diabetes related traits, such as fasting plasma glucose and obesity, and they discovered a number of associated loci ( $A D C Y 5$, DGKB, GCK, GCKR, MTNR1B, PROX1, BCDIN3D/FAIM2, AIF1/NCR3, FTO, GNPDA2, MCR4, NEGR1, SFRS10, SH2B1 and TMEM18) [21]-[26]. More recently many other polymorphisms have been added to the list of T2D associated loci reaching a number of over 400 common variants involved in this disease susceptibility [6] [7] [27].

Despite the high number of associated loci, genetics can explain less than $20 \%$ 
of type 2 diabetes heritability [28]. Moreover, investigating the role of genetics on T2D pathophysiological phenotypes, such as impaired beta cell function and insulin sensitivity, researchers found that insulin secretion was much more genetically determined than insulin action [16] [29] [30] [31] [32] [33]. Most of the GWA and meta-analysis studies have been conducted in Caucasians or Asian ancestry, however, as far as we know, there are no data regarding a quite large Italian sample. Thus, in this study, we aimed to genotyped 143 polymorphisms on 1875 Italian subjects (927 controls and 948 diabetic patients) in order to investigate their association with type 2 diabetes.

\section{Methods}

\subsection{The INCIPE Study}

INCIPE study (Initiative on Nephropathy, of relevance to public health, which is Chronic, possibly in its Initial stages, and carries a Potential risk of major clinical Endpoints) included 6200 patients, all Caucasians, $\geq 40$-years old by January 1 , 2006, randomly chosen from the lists of patients of 62 randomly selected general practitioners (GPs) based in four geographical areas in the Veneto region, Italy. In this study we reported data collected in 795 subjects, belonging to the INCIPE population and randomly selected. Enrolment and clinical examination were performed locally in four units, by trained medical doctors. After written informed consent was obtained, each participant completed a self-administered questionnaire (e.g., family and personal medical history, pharmacologic treatments, and smoking habits). Standard clinical parameters were assessed in all patients. Blood and urine samples were collected for each patient and processed at the Verona General Hospital, Central Laboratory [34].

\subsection{GENFIEV Study}

The GENFIEV study is a multicentre nationwide Italian study designed to recruit individuals with impaired glucose regulation (IGR) in the attempt to identify phenotypic and genotypic features that may allow the identification of subjects at high risk for T2D

(http://clinicaltrials.gov/ct2/show/NCT00879801?term=GENFIEV\&rank=1)

[35]. The study was approved by Institutional Review Boards, and all subjects gave written informed consent before entering the study. In this study we reported data collected in 439 subjects, belonging to the GENFIEV study. All subjects underwent a standardised medical history, physical examination and an OGTT (75 g) to assess beta cell function, as previously described [36]. Biochemical parameters were determined by standard methods on Roche-Modular Autoanalyzer (Milan, Italy). Serum C-peptide and insulin concentrations were measured centrally in the Pisa laboratory by immunoassay (Immulite, DPC; Los Angeles, CA, USA). The homeostasis model assessment of insulin resistance (HOMA-IR) index was calculated for all subjects as follows: [insulin (mU/L).glucose (mg/ $\mathrm{dL})] / 22.5$ and used as a fasting biomarker of insulin resistance [37]. 


\subsection{Verona Newly Diagnosed Type 2 Diabetes Study (VNDS)}

The VNDS is a cohort consisting of Caucasian patients with newly diagnosed type 2 diabetes, drug-naïve and GAD-antibodies negative (GAD65 < $1 \mathrm{KU} / \mathrm{L}$ ). As of January 1, 2002, all patients with T2D referred to the Diabetes Clinic embedded into the Division of Endocrinology, Diabetes and Metabolic Diseases of the University and Hospital Trust of Verona and whose disease was diagnosed in the past 6 months were offered to participate in this study. Recruitment was ended on December 31, 2015 and a follow-up was then planned and is ongoing. A detailed description of the experimental design has been previously published [38] [39]. In this study we reported data collected in 641 subjects, belonging to the VNDS. Each subject gave informed written consent before participating in the research, which was approved by the Human Investigation Committee of the Verona City Hospital. Standard clinical parameters were assessed in all patients. Metabolic tests were carried out on two separate days in random order. On one day an OGTT (75 g) was performed to assess beta cell function, as previously described [36]. On a separate day, a euglycemic insulin clamp was performed to assess insulin sensitivity [38] [39]. Plasma glucose concentration was measured in duplicate with a Beckman Glucose Analyzer II (Beckman Instruments, Fullerton, CA, USA) or a YSI 2300 Stat Plus Glucose\&Lactate Analyzer (YSI Inc., Yellow Springs, OH, USA), at bedside. Serum C-peptide and insulin concentrations were measured by chemiluminescence. Glycated hemoglobin and serum lipids were measured by standard in-house methods. GAD-antibodies were measured by immunoradiometry (CentAK, Medipan, Germany), according to manufacturer's instructions. The amount of glucose metabolized during the last 60 min of the clamp (M value) was computed with standard formulae [36].

In the GENFIEV and the VNDS a detailed assessment of beta cell function by state-of-art modelling of the glucose/C-peptide curves during the OGTT was performed, (details are reported in the Supplementary Material "Mathematical Modelling of Beta Cell Function Section” [41]-[47]).

\subsection{Subjects Classification}

Participants were classified as cases and controls on the basis of fasting plasma glucose values. Controls presented normal glucose tolerance having fasting blood glucose $(\mathrm{FPG}) \leq 7 \mathrm{mmol} / \mathrm{l}(\leq 126 \mathrm{mg} / \mathrm{dl})$, whereas, cases were T2D subjects having a clinical diagnosis of diabetes or an FPG value above $7 \mathrm{mmol} / \mathrm{L}(>126$ $\mathrm{mg} / \mathrm{dL}$ ). Firstly, were identified T2D subjects and then was identified the control group selecting subjects as similar as possible for sex and gender.

\subsection{Genotyping}

A peripheral blood sample was collected from each patient and the DNA was extracted by standard salting out method. Genotypes were assessed by the highthroughput genotyping Veracode technique (Illumina Inc, CA), applying the GoldenGate Genotyping Assay according to manufacturer's instructions [48]. For 
quality control (QC), only the samples and marker call rates $>90 \%$ were used. One hundred and thirty-three out of 143 polymorphisms have been successfully genotyped. Beyond the reported T2D associated polymorphisms, when possible, we selected also tag SNPs, through GEVALT software (GEnotype Visualization and ALgorithmic Tool) [49], in order to capture more that $90 \%$ of the common genetic variability of the genomic regions considered.

\subsection{Statistical Analysis}

Data are presented as medians and interquartile range, unless otherwise indicated. Hardy-Weinberg equilibrium was tested by chi-square test. Comparison between clinical and anthropometric features of cases and controls was performed by Mann-Whitney U test.

Type 2 diabetes association analyses, adjusted for age, gender and BMI, were carried out by logistic regression, using PLINK 1.07 [50]. Nominal statistical significance was declared at $\mathrm{p}<0.05$.

\section{Results}

\subsection{Clinical Features of Cases and Controls.}

The cohort was formed by 1875 subjects. Overall, 948 (50.6\%) had diabetes: 99 subjects of GENFIEV cohort, 208 of INCIPE cohort and the whole VNDS population $(n=641)$. Median and interquartile range of age, BMI and fasting plasma glucose according to controls and cases are reported in Table 1 and Table 2, respectively. Not surprisingly, type 2 diabetes patients were older $(\mathrm{p}=0.01)$, more obese $(\mathrm{p}=0.03)$ and with higher fasting plasma glucose levels $(\mathrm{p}<0.001)$ than controls.

\subsection{Association of 133 Polymorphisms to Type 2 Diabetes}

Ten polymorphisms failed the quality control and were not evaluated further. Allele distribution of the left 133 successfully genotyped polymorphisms was compatible with the Hardy-Weinberg equilibrium. A logistic regression analysis showed that 20 polymorphisms, located into 11 loci, were associated to type 2 diabetes, after adjustment for age, gender and BMI (Table 3). Four variants of TCF7L2 gene displayed the strongest signal in term of both Odd Ratio (OR) and p-value ( $\mathrm{p}<4 \times 10^{-7}$ or less). Other associated SNPs were located within $K C N J 11$, WFS1, ADAMTS9, IGF2BP2, ABCC8, JAZF1, FTO, HNF1B, G6PC2 and GCKR

Table 1. Controls clinical features. Data are presented as median [I.Q. range].

\begin{tabular}{cccc}
\hline Variable & $\underline{\text { Males }}$ & $\underline{\text { Females }}$ & $\underline{\text { All }}$ \\
\hline Number (M/F) & 517 & 410 & 927 \\
Age (yrs) & $57[48-64]$ & $54[43-63]$ & $56[46-64]$ \\
BMI (kg/m $\left.{ }^{2}\right)$ & $28[26-31]$ & $26[29-32.9]$ & $28.8[26-31]$ \\
Fasting P-glucose (mmol/l) & $5[4.7-5.3]$ & $4.9[4.6-5.2]$ & $5[4.6-5.2]$ \\
\hline
\end{tabular}


Table 2. Type 2 diabetes subjects clinical features. Data are presented as median [I.Q. range].

\begin{tabular}{cccc}
\hline Variable & $\underline{\text { Males }}$ & $\underline{\text { Females }}$ & $\underline{\text { All }}$ \\
\hline Number (M/F) & 623 & 325 & 948 \\
Age (yrs) & $59[50-66]$ & $62[57-68]$ & $60[52-67]$ \\
BMI (kg/m $\left.{ }^{2}\right)$ & $29[26-32.2]$ & $29.9[26.8-33.8]$ & $29.2[26.2-32.8]$ \\
Fasting P-glucose (mmol/1) & $7.2[6.3-8.1]$ & $7.4[6.4-8.5]$ & $7.3[6.4-8.3]$ \\
\hline
\end{tabular}

Table 3. Polymorphisms associated to type 2 diabetes. Data are presented as OR (95\% CI) and adjusted for age, sex, BMI.

\begin{tabular}{cccc}
\hline SNP & OR $(95 \%$ CI $)($ minor allele $)$ & p value & GENE \\
\hline rs7903146 & $1.57(1.36-1.81)$ & $7.72 \times 10^{-10}$ & TCF7L2 \\
rs12255372 & $1.54(1.33-1.78)$ & $3.62 \times 10^{-9}$ & TCF7L2 \\
rs7901695 & $1.49(1.29-1.72)$ & $5.84 \times 10^{-8}$ & TCF7L2 \\
rs11196205 & $1.42(1.24-1.62)$ & $4.13 \times 10^{-7}$ & TCF7L2 \\
rs1002226 & $1.28(1.11-1.47)$ & 0.0006 & KCNJ11 \\
rs6446482 & $1.28(1.11-1.48)$ & 0.0007 & WFS1 \\
rs5219 & $1.26(1.10-1.46)$ & 0.001 & KCNJ11 \\
rs7648557 & $1.24(1.09-1.42)$ & 0.002 & ADAMTS9 \\
rs10010131 & $1.25(1.08-1.43)$ & 0.002 & WFS1 \\
rs6789741 & $1.27(1.08-1.50)$ & 0.005 & IGF2BP2 \\
rs7129639 & $1.21(1.05-1.40)$ & 0.007 & ABCC8 \\
rs864745 & $1.20(1.05-1.38)$ & 0.009 & JAZF1 \\
rs7204916 & $1.18(1.03-1.35)$ & 0.016 & FTO \\
rs7501939 & $1.18(1.03-1.35)$ & 0.018 & HNF1B \\
rs4722760 & $1.21(1.03-1.42)$ & 0.023 & JAZF1 \\
rs7106053 & $1.20(1.02-1.40)$ & 0.027 & ABCC8 \\
rs13387347 & $1.18(1.02-1.36)$ & 0.027 & G6PC2 \\
rs780094 & $1.16(1.02-1.33)$ & 0.027 & HNF1B \\
rs1557780 & $1.17(1.02-1.34)$ & 0.032 & \\
rs2689 & $1.16(1.01-1.33)$ & & \\
\hline & & & \\
\hline
\end{tabular}

genes $(\mathrm{p}<0.038)$. Results regarding all other analyzed polymorphisms were reported in the Supplementary Material, Table S1.

\section{Discussion}

In this study we tested the association of 133 polymorphisms, in part already identified as T2D associated loci and in part selected as tag SNP within loci of interest, with type 2 diabetes on 1875 Italian subjects (927 controls and 948 cases). 
The novelty of the study is that, as far as we know, this is the first study that investigated a number of polymorphisms, already associated to type 2 diabetes or located into/close to genes with a possible biological role in the development of the disease, in a quite large Italian population, thus giving information about the allelic frequency of these SNPs in Italians subjects.

Not surprisingly, TCF7L2 variants displayed the strongest association signals, and this was consistent with previously published data, reporting for rs7903146 the highest odd ratio (OR: 1.37) of all type 2 diabetes associated polymorphisms, in different ethnic groups [51] [52] [53]. Different mechanisms have been hypothesized in order to explain the biological role of TCF7L2 in determining type 2 diabetes, particularly it could: 1) decrease beta cell proliferation and insulin secretion; 2) alter insulin process or release; 3) affect GLP1 signalling in beta cell [54]; 4) alter local chromatin structure in islet cells [55].

Three loci, reported in this study, have been previously associated to type 2 diabetes through candidate-gene approach: KCNJ11 and $A B C C 8$, both encoding two subunits of the potassium channel, an important protein involved in the insulin release process [56] [57]; and WFS1, which is involved in the Wolfram Syndrome, a monogenic disease characterized also by diabetes mellitus [58]. Particularly, variants in WFS1 have been linked to gut incretin hormones such as pancreatic glucose-dependent insulinotropic peptide sensitivity. Because endoplasmic reticulum stress has been recognized as contributing to insulin resistance in type 2 diabetes [59], the dissection of pathogenic mechanisms in monogenic ER stress-mediated $\beta$-cell loss may also contribute to the understanding of type 2 diabetes pathogenesis [60].

All other associated variants have been previously identified through GWA studies [3] [4] [5] [6] [7]. Many of them have a biological role that could explain their involvement in type 2 diabetes, even if the molecular mechanisms are not yet clear and further functional studies are needed: IGF2BP2, which binds IGF2 mRNA and influences pancreas development [3] [61]; FTO, the strongest obesity gene so far identified, which probably promotes diabetes onset through an effect on BMI [62]; HNF1B, which regulates gene transcription of insulin and other proteins involved in glucose metabolism [63]; finally $G 6 P C 2$, belonging to the glucose-6-phosphatase catalytic subunit family, and $G C K R$, the glucokinase regulatory protein, both involved in glucose metabolism, previously associated to fasting glucose levels and type 2 diabetes [64]. Glucokinase and glucose-6-phosphatase are the molecular bases of the glucose/glucose-6-phosphate cycle, which directly affects the glucose homeostasis through insulin secretion. Notably, the association between G6PC2 SNPs and FPG was reported only in non-diabetic population, but not in T2D cohorts [65].

Moreover, we previously demonstrated that $G C K R$ variability may play a pathogenetic role in type 2 diabetes affecting insulin secretion [40]. These three genes could be considered as determinants of glucose homeostasis that finely regulate beta cell function [40] [64].

The biological function of the last two loci that we found associated to type 2 
diabetes in our Italian population, JAZF1 and ADAMTS9, and that have been already identified in previous GWAS, is not yet well known, thus it is difficult to hypothesize their possible functional mechanisms in type 2 diabetes [12] [13], even because contrasting results have been found [66]. We previously demonstrated that variations in $A D A M T S 9$ were related to insulin secretion and a recent study of Cheng and colleagues indicated a positive regulatory role of TCF7L2 on endogenous ADAMTS9 expression [63] [67]. JAZF1 has been implicated in glucose and metabolism, and its overexpression could result in enhanced glucose tolerance and insulin sensitivity, reduced body weight gain, inhibited the expression of genes related to lipid metabolism and lipid accumulation in adipocytes [68] [69] [70] [71]. A recent study of Kobiita A. et al., shows that impaired JAZF1 function in T2D contributes to ribosomal and ER stress, activation of apoptosis pathways, and ultimately $\beta$-cell demise [72].

\section{Conclusion}

In conclusion, we replicated the association of 11 loci with type 2 diabetes in an Italian population, further genetic and functional studies will be necessary to identify the causal variants, if any, located into these T2D-associated loci.

\section{Conflicts of Interest}

The authors have no potential conflicts of interest to disclose.

\section{References}

[1] International Diabetes Federation (2017) IDF Diabetes Atlas. 8th Edition, International Diabetes Federation, Brussels.

[2] DeFronzo, R.A., Ferrannini, E., Groop, L., Henry, R.R., Herman, W.H., Holst, J.J., et al. (2015) Type 2 Diabetes Mellitus. Nature Reviews Disease Primers, 1, Article No. 15019. https://doi.org/10.1038/nrdp.2015.19

[3] Ridderstråle, M. and Groop, L. (2009) Genetic Dissection of Type 2 Diabetes. Molecular and Cellular Endocrinology, 297, 10-17. https://doi.org/10.1016/j.mce.2008.10.002

[4] Almind, K., Bjørbaek, C., Vestergaard, H., Hansen, T., Echwald, S. and Pedersen, O. (1993) Aminoacid Polymorphisms of Insulin Receptor Substrate-1 in Non-InsulinDependent Diabetes Mellitus. Lancet, 342, 828-832. https://doi.org/10.1016/0140-6736(93)92694-O

[5] Visscher, P.M., Wray, N.R., Zhang, Q., Sklar, P., McCarthy, M.I., Brown, M.A. and Yang, J. (2017) 10 Years of GWAS Discovery: Biology, Function, and Translation. American Journal of Human Genetics, 101, 5-22. https://doi.org/10.1016/j.ajhg.2017.06.005

[6] Vujkovic, M., Keaton, J.M., Lynch, J.A., Miller, D.R., Zhou, J., Tcheandjieu, C., et al. (2020) Discovery of 318 New Risk Loci for Type 2 Diabetes and Related Vascular Outcomes among 1.4 Million Participants in a Multi-Ancestry Meta-Analysis. Nature Genetics, 52, 680-691. https://doi.org/10.1101/19012690

[7] Mahajan, A., Taliun, D., Thurner, M., Robertson, N.R., Torres, J.M., Rayner, N.W., et al. (2018) Fine-Mapping Type 2 Diabetes Loci to Single-Variant Resolution Using 
High-Density Imputation and Islet-Specific Epigenome Maps. Nature Genetics, 50, 1505-1513. https://doi.org/10.1038/s41588-018-0241-6

[8] Sladek, R., Rocheleau, G., Rung, J., Dina, C., Shen, L., Serre, D., Boutin, P., Vincent, D., Belisle, A., Hadjadj, S., Balkau, B., Heude, B., Charpentier, G., Hudson, T.J., Montpetit, A., Pshezhetsky, A.V., Prentki, M., Posner, B.I., Balding, D.J., Meyre, D., Polychronakos, C. and Froguel, P. (2007) A Genome-Wide Association Study Identifies Novel Risk Loci for Type 2 Diabetes. Nature, 445, 881-885.

https://doi.org/10.1038/nature05616

[9] Scott, L.J., Mohlke, K.L., Bonnycastle, L.L., Willer, C.J., Li, Y., Duren, W.L., et al. (2007) A Genome-Wide Association Study of Type 2 Diabetes in Finns Detects Multiple Susceptibility Variants. Science, 316, 1341-1345.

https://doi.org/10.1126/science.1142382

[10] Zeggini, E., Weedon, M.N., Lindgren, C.M., Frayling, T.M., Elliott, K.S., Lango, H., et al. (2007) Replication of Genome-Wide Association Signals in UK Samples Reveals Risk Loci for Type 2 Diabetes. Science, 316, 1336-41. [Erratum in: Science, 2007, 317(5841): 1035-1036]

[11] Diabetes Genetics Initiative of Broad Institute of Harvard and MIT, Lund University, and Novartis Institutes of BioMedical Research, Saxena, R., Voight, B.F., Lyssenko, V., Burtt, N.P., de Bakker, P.I., Chen, H., et al. (2007) Genome-Wide Association Analysis Identifies Loci for Type 2 Diabetes and Triglyceride Levels. Science, 316, 1331-1336. https://doi.org/10.1126/science.1142358

[12] Zeggini, E., Scott, L.J., Saxena, R., Voight, B.F., Marchini, J.L., Hu, T., et al. (2008) Meta-Analysis of Genome-Wide Association Data and Large-Scale Replication Identifies Additional Susceptibility Loci for Type 2 Diabetes. Nature Genetics, 40, 638-645. https://doi.org/10.1038/ng.120

[13] Grarup, N., Andersen, G., Krarup, N.T., Albrechtsen, A., Schmitz, O., Jørgensen, T., Borch-Johnsen, K., Hansen, T. and Pedersen, O. (2008) Association Testing of Novel Type 2 Diabetes Risk Alleles in the JAZF1, CDC123/CAMK1D, TSPAN8, THADA, ADAMTS9, and NOTCH2 Loci with Insulin Release, Insulin Sensitivity, and Obesity in a Population-Based Sample of 4,516 Glucose-Tolerant Middle-Aged Danes. Diabetes, 57, 2534-2540. https://doi.org/10.2337/db08-0436

[14] Yasuda, K., Miyake, K., Horikawa, Y., Hara, K., Osawa, H., Furuta, H., et al. (2008) Variants in KCNQ1 Are Associated with Susceptibility to Type 2 Diabetes Mellitus. Nature Genetics, 40, 1092-1097. https://doi.org/10.1038/ng.207

[15] Unoki, H., Takahashi, A., Kawaguchi, T., Hara, K., Horikoshi, M., Andersen, G., et al. (2008) SNPs in KCNQ1 Are Associated with Susceptibility to Type 2 Diabetes in East Asian and European Populations. Nature Genetics, 40, 1098-1102. https://doi.org/10.1038/ng.208

[16] Voight, B.F., Scott, L.J., Steinthorsdottir, V., Morris, A.P., Dina, C., Welch, R.P., et al. (2010) Twelve Type 2 Diabetes Susceptibility Loci Identified through Large-Scale Association Analysis. Nature Genetics, 42, 579-589. https://doi.org/10.1038/ng.609

[17] Tarasov, A.I., Nicolson, T.J., Riveline, J.P., Taneja, T.K., Baldwin, S.A., Baldwin, J.M., Charpentier, G., Gautier, J.F., Froguel, P., Vaxillaire, M. and Rutter, G.A. (2008) A Rare Mutation in $A B C C 8 /$ SUR1 Leading to Altered ATP-Sensitive $\mathrm{K}+$ Channel Activity and Beta-Cell Glucose Sensing Is Associated with Type 2 Diabetes in Adults. Diabetes, 57, 1595-1604. https://doi.org/10.2337/db07-1547

[18] Bonnycastle, L.L., Willer, C.J., Conneely, K.N., Jackson, A.U., Burrill, C.P., Watanabe, R.M., et al. (2006) Common Variants in Maturity-Onset Diabetes of the Young Genes Contribute to Risk of Type 2 Diabetes in Finns. Diabetes, 55, 2534-2540. 
https://doi.org/10.2337/db06-0178

[19] Johansson, S., Raeder, H., Eide, S.A., Midthjell, K., Hveem, K., Søvik, O., Molven, A. and Njølstad, P.R. (2007) Studies in 3,523 Norwegians and Meta-Analysis in 11,571 Subjects Indicate That Variants in the Hepatocyte Nuclear Factor 4 Alpha (HNF4A) P2 Region Are Associated with Type 2 Diabetes in Scandinavians. Diabetes, 56, 3112-3117. https://doi.org/10.2337/db07-0513

[20] Weedon, M.N., Owen, K.R., Shields, B., Hitman, G., Walker, M., McCarthy, M.I., Love-Gregory, L.D., Permutt, M.A., Hattersley, A.T. and Frayling, T.M. (2004) Common Variants of the Hepatocyte Nuclear Factor-4a P2 Promoter Are Associated with Type 2 Diabetes in the U.K. Population. Diabetes, 53, 3002-3006. https://doi.org/10.2337/diabetes.53.11.3002

[21] Dupuis, J., Langenberg, C., Prokopenko, I., Saxena, R., Soranzo, N., Jackson, A.U., et al. (2010) New Genetic Loci Implicated in Fasting Glucose Homeostasis and Their Impact on Type 2 Diabetes Risk. Nature Genetics, 42, 105-116.

[22] Prokopenko, I., Langenberg, C., Florez, J.C., Saxena, R., Soranzo, N., Thorleifsson, G., et al. (2009) Variants in MTNR1B Influence Fasting Glucose Levels. Nature Genetics, 41, 77-81. https://doi.org/10.1038/ng.290

[23] Renström, F., Payne, F., Nordström, A., Brito, E.C., Rolandsson, O., Hallmans, G., Barroso, I., Nordström, P. and Franks, P.W.; GIANT Consortium (2009) Replication and Extension of Genome-Wide Association Study Results for Obesity in 4923 Adults from Northern Sweden. Human Molecular Genetics, 18, 1489-1496. https://doi.org/10.1093/hmg/ddp041

[24] Frayling, T.M., Timpson, N.J., Weedon, M.N., Zeggini, E., Freathy, R.M., Lindgren, C.M., et al. (2007) A Common Variant in the FTO Gene Is Associated with Body Mass Index and Predisposes to Childhood and Adult Obesity. Science, 316, 889-894. https://doi.org/10.1126/science.1141634

[25] Chambers, J.C., Elliott, P., Zabaneh, D., Zhang, W., Li, Y., Froguel, P., Balding, D., Scott, J. and Kooner, J.S. (2008) Common Genetic Variation near MC4R Is Associated with Waist Circumference and Insulin Resistance. Nature Genetics, 40, 716-718. https://doi.org/10.1038/ng.156

[26] Thorleifsson, G., Walters, G.B., Gudbjartsson, D.F., Steinthorsdottir, V., Sulem, P., Helgadottir, A., et al. (2009) Genome-Wide Association Yields New Sequence Variants at Seven Loci That Associate with Measures of Obesity. Nature Genetics, 41, 18-24. https://doi.org/10.1038/ng.274

[27] Suzuki, K., Akiyama, M., Ishigaki, K., Kanai, M., Hosoe, J., Shojima, N., et al. (2019) Identification of 28 New Susceptibility Loci for Type 2 Diabetes in the Japanese Population. Nature Genetics, 51, 379-386. https://doi.org/10.1038/s41588-018-0332-4

[28] Prasad, R.B. and Groop, L. (2019) Precision Medicine in Type 2 Diabetes. Journal of Internal Medicine, 285, 40-48. https://doi.org/10.1111/joim.12859

[29] Pal, A. and McCarthy, M.I. (2013) The Genetics of Type 2 Diabetes and Its Clinical Relevance. Clinical Genetics, 83, 297-306. https://doi.org/10.1111/cge.12055

[30] Keller, M.P., Rabaglia, M.E., Schueler, K.L., Stapleton, D.S., Gatti, D.M., Vincent, M., Mitok, K.A., Wang, Z., Ishimura, T., Simonett, S.P., Emfinger, C.H., Das, R., Beck, T., Kendziorski, C., Broman, K.W., Yandell, B.S., Churchill, G.A. and Attie, A.D. (2019) Gene Loci Associated with Insulin Secretion in Islets from Non-Diabetic Mice. Journal of Clinical Investigation, 129, 4419-4432. https://doi.org/10.1172/JCI129143

[31] Peiris, H., Park, S., Louis, S., Gu, X., Lam, J.Y., Asplund, O., Ippolito, G.C., Bottino, 
R., Groop, L., Tucker, H. and Kim, S.K. (2018) Discovering Human Diabetes-Risk Gene Function with Genetics and Physiological Assays. Nature Communications, 9, Article No. 3855. https://doi.org/10.1038/s41467-018-06249-3

[32] Czech, M.P. (2017) Insulin Action and Resistance in Obesity and Type 2 Diabetes. Nature Medicine, 23, 804-814. https://doi.org/10.1038/nm.4350

[33] Kahn, S.E., Suvag, S., Wright, L.A. and Utzschneider, K.M. (2012) Interactions between Genetic Background, Insulin Resistance and $\beta$-Cell Function. Diabetes Obesity and Metabolism, 14, 46-56. https://doi.org/10.1111/j.1463-1326.2012.01650.x

[34] Gambaro, G., Yabarek, T., Graziani, M.S., Gemelli, A., Abaterusso, C., Frigo, A.C., Marchionna, N., Citron, L., Bonfante, L., Grigoletto, F., Tata, S., Ferraro, P.M., Legnaro, A., Meneghel, G., Conz, P., Rizzotti, P., D’Angelo, A. and Lupo, A.; INCIPE Study Group (2010) Prevalence of CKD in Northeastern Italy: Results of the INCIPE Study and Comparison with NHANES. Clinical Journal of the American Society of Nephrology, 5, 1946-1953. https://doi.org/10.2215/CJN.02400310

[35] Bianchi, C., Miccoli, R., Trombetta, M., Giorgino, F., Frontoni, S., Faloia, E., Marchesini, G., Dolci, M.A., Cavalot, F., Cavallo, G., Leonetti, F., Bonadonna, R.C. and Del Prato, S.; GENFIEV Investigators (2013) Elevated 1-Hour Postload Plasma Glucose Levels Identify Subjects with Normal Glucose Tolerance but Impaired $\beta$-Cell Function, Insulin Resistance, and Worse Cardiovascular Risk Profile: The GENFIEV Study. The Journal of Clinical Endocrinology \& Metabolism, 98, 2100-2105. https://doi.org/10.1210/jc.2012-3971

[36] Bonadonna, R.C., Heise, T., Arbet-Engels, C., Kapitza, C., Avogaro, A., Grimsby, J., Zhi, J., Grippo, J.F. and Balena, R. (2010) Piragliatin (RO4389620), a Novel Glucokinase Activator, Lowers Plasma Glucose Both in the Postabsorptive State and after a Glucose Challenge in Patients with Type 2 Diabetes Mellitus: A Mechanistic Study. The Journal of Clinical Endocrinology \& Metabolism, 95, 5028-5036. https://doi.org/10.1210/jc.2010-1041

[37] Matthews, D.R., Hosker, J.P., Rudenski, A.S., Naylor, B.A., Treacher, D.F. and Turner, R.C. (1985) Homeostasis Model Assessment: Insulin Resistance and Beta-Cell Function from Fasting Plasma Glucose and Insulin Concentrations in Man. Diabetologia, 28, 412-419. https://doi.org/10.1007/BF00280883

[38] Bonetti, S., Trombetta, M., Malerba, G., Boselli, L., Trabetti, E., Muggeo, M., et al. (2011) Variants and Haplotypes of TCF7L2 Are Associated with $\beta$-Cell Function in Patients with Newly Diagnosed Type 2 Diabetes: The Verona Newly Diagnosed Type 2 Diabetes Study (VNDS) 1. The Journal of Clinical Endocrinology \& Metabolism, 96, E389-E393. https://doi.org/10.1210/jc.2010-1677

[39] Bonora, E., Trombetta, M., Dauriz, M., Travia, D., Cacciatori, V., Brangani, C., et al. (2020) Chronic Complications in Patients with Newly Diagnosed Type 2 Diabetes: Prevalence and Related Metabolic and Clinical Features: The Verona Newly Diagnosed Type 2 Diabetes Study (VNDS) 9. BMJ Open Diabetes Res Care, 8, e001549. https://doi.org/10.1136/bmjdrc-2020-001549

[40] Bonetti, S., Trombetta, M., Boselli, M.L., Turrini, F., Malerba, G., Trabetti, E., Pignatti, P.F., Bonora, E. and Bonadonna, R.C. (2011) Variants of GCKR Affect Both $\beta$-Cell and Kidney Function in Patients with Newly Diagnosed Type 2 Diabetes: The Verona Newly Diagnosed Type 2 Diabetes Study 2. Diabetes Care, 34, 1205-1210. https://doi.org/10.2337/dc10-2218

[41] Cali, A.M., Bonadonna, R.C., Trombetta, M., Weiss, R. and Caprio, S. (2008) Metabolic Abnormalities Underlying the Different Prediabetic Phenotypes in Obese Adolescents. The Journal of Clinical Endocrinology \& Metabolism, 93, 1767-1773. https://doi.org/10.1210/jc.2007-1722 
[42] Weiss, R., Caprio, S., Trombetta, M., Taksali, S.E., Tamborlane, W.V. and Bonadonna, R. (2005) Beta-Cell Function across the Spectrum of Glucose Tolerance in Obese Youth. Diabetes, 54, 1735-1743. https://doi.org/10.2337/diabetes.54.6.1735

[43] Cobelli, C., Toffolo, G.M., Dalla Man, C., et al. (2007) Assessment of Beta-Cell Function in Humans, Simultaneously with Insulin Sensitivity and Hepatic Extraction, from Intravenous and Oral Glucose Tests. American Journal of Physiology-Endocrinology and Metabolism, 293, E1-E15. https://doi.org/10.1152/ajpendo.00421.2006

[44] Mari, A., Camastra, S., Toschi, E., et al. (2001) A Model for Glucose Control of Insulin Secretion during 24 h of Free Living. Diabetes, 50, S164-S168. https://doi.org/10.2337/diabetes.50.2007.S164

[45] Van Cauter, E., Mestrez, F., Sturis, J. and Polonsky, K.S. (1992) Estimation of Insulin Secretion Rates from C-Peptide Levels. Comparison of Individual and Standard Kinetic Parameters for C-Peptide Clearance. Diabetes, 41, 368-377.

[46] Toschi, E., Camastra, S., Sironi, A.M., et al. (2002) Effect of Acute Hyperglycemia on Insulin Secretion in Humans. Diabetes, 51, S130-S133.

https://doi.org/10.2337/diabetes.51.2007.S130

[47] Foster, D.M., Boston, R.C., Jacquez, J.A. and Zech, L. (1989) A Resource Facility for Kinetic Analysis: Modeling Using the SAAM Computer Programs. Health Physics, 57, 457-466. https://doi.org/10.1097/00004032-198907001-00063

[48] Lin, C.H., Yeakley, J.M., McDaniel, T.K. and Shen, R. (2009) Medium- to High-Throughput SNP Genotyping Using VeraCode Microbeads. Methods in Molecular Biology, 496, 129-142. https://doi.org/10.1007/978-1-59745-553-4 10

[49] Davidovich, O., Kimmel, G. and Shamir, R. (2007) GEVALT: An Integrated Software Tool for Genotype Analysis. BMC Bioinformatics, 8, Article No. 36. https://doi.org/10.1186/1471-2105-8-36

[50] Purcell, S., Neale, B., Todd-Brown, K., Thomas, L., Ferreira, M.A., Bender, D., Maller, J., Sklar, P., de Bakker, P.I., Daly, M.J. and Sham, P.C. (2007) PLINK: A Tool Set for Whole-Genome Association and Population-Based Linkage Analyses. American Journal of Human Genetics, 81, 559-575. https://doi.org/10.1086/519795

[51] Grant, S.F., Thorleifsson, G., Reynisdottir, I., Benediktsson, R., Manolescu, A., Sainz, J., et al. (2006) Variant of Transcription Factor 7-Like 2 (TCF7L2) Gene Confers Risk of Type 2 Diabetes. Nature Genetics, 38, 320-323. https://doi.org/10.1038/ng1732

[52] Cauchi, S., El Achhab, Y., Choquet, H., Dina, C., Krempler, F., Weitgasser, R., Nejjari, C., Patsch, W., Chikri, M., Meyre, D. and Froguel, P. (2007) TCF7L2 Is Reproducibly Associated with Type 2 Diabetes in Various Ethnic Groups: A Global Meta-Analysis. Journal of Molecular Medicine (Ber), 85, 777-782. https://doi.org/10.1007/s00109-007-0203-4

[53] Vaxillaire, M., Veslot, J., Dina, C., Proença, C., Cauchi, S., Charpentier, G., Tichet, J., Fumeron, F., Marre, M., Meyre, D., Balkau, B. and Froguel, P.; DESIR Study Group (2008) Impact of Common Type 2 Diabetes Risk Polymorphisms in the DESIR Prospective Study. Diabetes, 57, 244-254. https://doi.org/10.2337/db07-0615

[54] Pearson, E.R. (2009) Translating TCF7L2: From Gene to Function. Diabetologia, 52, 1227-1230. https://doi.org/10.1007/s00125-009-1356-1

[55] Gaulton, K.J., Nammo, T., Pasquali, L., Simon, J.M., Giresi, P.G., Fogarty, M.P., Panhuis, T.M., Mieczkowski, P., Secchi, A., Bosco, D., Berney, T., Montanya, E., Mohlke, K.L., Lieb, J.D. and Ferrer, J. (2010) A Map of Open Chromatin in Human Pancreatic Islets. Nature Genetics, 42, 255-259. https://doi.org/10.1038/ng.530 
[56] Laukkanen, O., Pihlajamäki, J., Lindström, J., Eriksson, J., Valle, T.T., Hämäläinen, H., Ilanne-Parikka, P., Keinänen-Kiukaanniemi, S., Tuomilehto, J., Uusitupa, M. and Laakso, M.; Finnish Diabetes Prevention Study Group (2004) Polymorphisms of the SUR1 ( $A B C C 8)$ and Kir6.2 (KCNJ11) Genes Predict the Conversion from Impaired Glucose Tolerance to Type 2 Diabetes. The Finnish Diabetes Prevention Study. The Journal of Clinical Endocrinology \& Metabolism, 89, 6286-6290. https://doi.org/10.1210/jc.2004-1204

[57] Qin, L.J., Lv, Y. and Huang, Q.Y. (2013) Meta-Analysis of Association of Common Variants in the KCNJ11-ABCC8 Region with Type 2 Diabetes. Genetics and Molecular Research, 12, 2990-3002. https://doi.org/10.4238/2013.August.20.1

[58] Wasson, J. and Permutt, M.A. (2008) Candidate Gene Studies Reveal That the WFS1 Gene Joins the Expanding List of Novel Type 2 Diabetes Genes. Diabetologia, 51, 391-393. https://doi.org/10.1007/s00125-007-0920-9

[59] Eizirik, D.L., Cardozo, A.K. and Cnop, M. (2008) The Role for Endoplasmic Reticulum Stress in Diabetes Mellitus. Endocrine Reviews, 29, 42-61.

https://doi.org/10.1210/er.2007-0015

[60] Rohayem, J., Ehlers, C., Wiedemann, B., et al. (2011) Diabetes and Neurodegeneration in Wolfram Syndrome: A Multicenter Study of Phenotype and Genotype. Diabetes Care, 34, 1503-1510. https://doi.org/10.2337/dc10-1937

[61] Zeggini, E. (2007) A New Era for Type 2 Diabetes Genetics. Diabetic Medicine, 24, 1181-1186. https://doi.org/10.1111/j.1464-5491.2007.02274.x

[62] Loos, R.J.F. and Yeo, G.S.H. (2014) The Bigger Picture of FTO: The First GWASIdentified Obesity Gene. Nature Reviews Endocrinology, 10, 51-61.

https://doi.org/10.1038/nrendo.2013.227

[63] Cheng, M., Huang, X., Zhang, M. and Huang, Q. (2020) Computational and Functional Analyses of T2D GWAS SNPs for Transcription Factor Binding. Biochemical and Biophysical Research Communications, 523, 658-665. https://doi.org/10.1016/j.bbrc.2019.12.086

[64] Wang, H., Liu, L., Zhao, J., Cui, G., Chen, C., Ding, H. and Wang, D.W. (2013) Large Scale Meta-Analyses of Fasting Plasma Glucose Raising Variants in $G C K$, GCKR, MTNR1B and G6PC2 and Their Impacts on Type 2 Diabetes Mellitus Risk. PLoS One, 8, e67665. https://doi.org/10.1371/journal.pone.0067665

[65] Shi, Y., Li, Y., Wang, J., Wang, C., Fan, J., Zhao, J., et al. (2017) Meta-Analyses of the Association of G6PC2 Allele Variants with Elevated Fasting Glucose and Type 2 Diabetes. PLoS One, 12, e0181232. https://doi.org/10.1371/journal.pone.0181232

[66] Schleinitz, D., Tönjes, A., Böttcher, Y., Dietrich, K., Enigk, B., Koriath, M., Scholz, G.H., Blüher, M., Zeggini, E., McCarthy, M.I., Kovacs, P. and Stumvoll, M. (2010) Lack of Significant Effects of the Type 2 Diabetes Susceptibility Loci JAZF1, CDC123/CAMK1D, NOTCH2, ADAMTS9, THADA, and TSPAN8/LGR5 on Diabetes and Quantitative Metabolic Traits. Hormone and Metabolic Research, 42, 14-22. https://doi.org/10.1055/s-0029-1233480

[67] Trombetta, M., Bonetti, S., Boselli, M.L., Miccoli, R., Trabetti, E., Malerba, G., Pignatti, P.F., Bonora, E., Del Prato, S. and Bonadonna, R.C. (2013) PPARG2 Pro12Ala and ADAMTS9 rs4607103 as "Insulin Resistance Loci" and "Insulin Secretion Loci" in Italian Individuals. The GENFIEV Study and the Verona Newly Diagnosed Type 2 Diabetes Study (VNDS) 4. Acta Diabetologica, 50, 401-408. https://doi.org/10.1007/s00592-012-0443-9

[68] Li, X., Yang, M., Wang, H., Jia, Y., Yan, P., Boden, G., Yang, G. and Li, L. (2014) Overexpression of JAZF1 Protected ApoE-Deficient Mice from Atherosclerosis by 
Inhibiting Hepatic Cholesterol Synthesis via CREB-Dependent Mechanisms. International Journal of Cardiology, 177, 100-110.

https://doi.org/10.1016/j.ijcard.2014.09.007

[69] Yuan, L., Luo, X., Zeng, M., Zhang, Y., Yang, M., Zhang, L., Liu, R., Boden, G., Liu, H., Ma, Z.A., Li, L. and Yang, G. (2015) Transcription Factor TIP27 Regulates Glucose Homeostasis and Insulin Sensitivity in a PI3-Kinase/Akt-Dependent Manner in Mice. International Journal of Obesity (Lond), 39, 949-958.

https://doi.org/10.1038/ijo.2015.5

[70] Yuan, L., Luo, X., Zeng, M., Zhang, Y., Yang, M., Zhang, L., Liu, R., Boden, G., Liu, H., Ma, Z.A., Li, L. and Yang, G. (2015) Transcription Factor TIP27 Regulates Glucose Homeostasis and Insulin Sensitivity in a PI3-Kinase/Akt-Dependent Manner in Mice. International Journal of Obesity, 39, 949-958.

https://doi.org/10.1038/ijo.2015.5

[71] Ming, G.F., Xiao, D., Gong, W.J., Liu, H.X., Liu, J., Zhou, H.H. and Liu, Z.Q. (2014) JAZF1 Can Regulate the Expression of Lipid Metabolic Genes and Inhibit Lipid Accumulation in Adipocytes. Biochemical and Biophysical Research Communications, 445, 673-680. https://doi.org/10.1016/j.bbrc.2014.02.088

[72] Kobiita, A., Godbersen, S., Araldi, E., Ghoshdastider, U., Schmid, M.W., Spinas, G., Moch, H. and Stoffel, M. (2020) The Diabetes Gene JAZF1 Is Essential for the Homeostatic Control of Ribosome Biogenesis and Function in Metabolic Stress. Cell Reports, 32, 107846. https://doi.org/10.1016/j.celrep.2020.107846 


\section{Supporting Information}

\section{Common variants associated to type 2 diabetes in the Italian population. Mathematical Modeling of Beta Cell Function}

The analysis of the glucose and C-peptide curves during the OGTT follows the general strategy described in previous publications [41] [42] with some modifications and builds upon previous works from other laboratories [43] [44]. The kinetics of C-peptide is described with a two-compartment model, in which the two pools (1 and 2) exchange with each other and the irreversible loss of the hormone is from pool 1, the same where C-peptide concentration is measured. C-peptide kinetic parameters are computed according to the equations by Van Cauter et al. [45].

Herein are the equations describing the model of glucose induced insulin secretion during an OGTT:

$$
\mathrm{d} c p_{1}(t) / \mathrm{d} t=\operatorname{ISR}(t)+c p_{2} \cdot k_{12}-\left(k_{01}+k_{21}\right) \cdot c p_{1}
$$

where ISR $=$ insulin secretion rate, $c p_{1}=\mathrm{C}$-peptide mass in the sampling (accessible) compartment, $c p_{2}=\mathrm{C}$-peptide mass in the remote compartment, $k_{12}$ and $k_{21}=$ rate constants of the exchange between the two C-peptide compartments, and $k_{01}=$ rate constant of the irreversible loss of C-peptide from the accessible compartment. Note that the values of the volume of distribution of C-peptide pool 1 (accessible compartment), $k_{12}, k_{21}$, and $k_{01}$ are computed according to the equations by Van Cauter et al. [45].

$$
\operatorname{ISR}(t)=\operatorname{BSR}+\operatorname{DSR}(t)+\operatorname{PSR}(t)
$$

where $\mathrm{BSR}=$ basal insulin secretion rate, DSR = insulin secretion rate due to the derivative (or dynamic) component, and PSR = insulin secretion rate due the proportional (or static) component.

$$
\mathrm{BSR}=C P_{s s} \cdot V_{1} \cdot k_{01}
$$

where $C P_{s s}$ is basal C-peptide concentration and $V_{1}$ is the volume of the accessible compartment of C-peptide.

From the modeling viewpoint, $\operatorname{DSR}(t)$ and $\operatorname{PSR}(t)$ are the components which in intravenous glucose tolerance tests or hyperglycemic clamps describe classical first phase insulin secretion and second phase insulin secretion, respectively. Furthermore, from a physiological viewpoint, the sum of BSR and $\operatorname{PSR}(t)$ describes the relationship linking glucose concentration and insulin secretion rate, in the absence of the derivative component (DSR).

$\operatorname{DSR}(t)$ and PSR $(\mathrm{t})$ are mathematically defined as follows:

$$
\begin{gathered}
\operatorname{DSR}(t)=X_{1}(t) \cdot \tau^{-1} \\
\mathrm{~d} X_{1}(t) / \mathrm{d} t=\sigma_{1} \cdot[\mathrm{d} G(t) / \mathrm{d} t] /[\log (1.1+t)]-X_{1}(t) \cdot \tau^{-1} \quad \text { if } \mathrm{d} G(t) / \mathrm{d} t>0 \\
\mathrm{~d} X_{1}(t) / \mathrm{d} t=-X_{1}(t) \cdot \tau^{-1} \quad \text { if } \mathrm{d} G(t) / \mathrm{d} t \leq 0
\end{gathered}
$$

where $\sigma_{1}=$ glucose sensitivity of derivative control of insulin secretion, $G=$ plasma glucose concentration, $X_{1}=$ C-peptide (insulin) mass made available for 
the derivative component of insulin secretion, $\tau=$ time constant of the derivative component of insulin secretion, and the term $\log (1.1+t)$ accomodates the time-associated decline of $\sigma_{1}$ documented in humans during a hyperglycemic stimulus [46].

$$
\begin{gathered}
\operatorname{PSR}(t)=X_{2}(t) \cdot \delta^{-1} \\
\mathrm{~d} X_{2}(t) / \mathrm{d} t=\sigma_{2} \cdot[G(t)-\theta]-X_{2}(t) \cdot \delta^{-1}
\end{gathered}
$$

where $\sigma_{2}=$ glucose sensitivity of the proportional component of insulin secretion, $X_{2}=$ C-peptide (insulin) mass made available for the proportional component of insulin secretion, $\delta=$ time constant of the proportional component of insulin secretion, $\theta=$ glucose threshold above which the beta-cell responds with the proportional component of insulin secretion to plasma glucose concentration.

This model was implemented in the SAAM 1.2 software (SAAM Institute, Seattle, WA) [47] to estimate its unknown parameters. Numerical values of the unknown parameters were estimated by using nonlinear least squares. Weights were chosen optimally, i.e., equal to the inverse of the variance of the measurement errors, which were assumed to be additive, uncorrelated, with zero mean, and a coefficient of variation (CV) of $6 \%-8 \%$. The unknown parameters of the model are: $C P_{s s}, \sigma_{1}, \tau, \sigma_{2}, \delta$, and $\theta$. They were estimated with good precision, as shown by their CVs (Supplemental Table S1). Since in the GENFIEV Study the data set was to the time window $0^{\prime}-120^{\prime}$, CPss was assumed to be equal to baseline C-peptide concentration in all subjects. For the same reasons, in those subjects of the GENFIEV Study in whom glucose levels did not go back close to baseline levels, $\theta$ was assumed to be equal to baseline glucose concentration.

Table S1. Association of the analysed polymorphisms with type 2 diabetes. Data are presented as OR (95\% Confidence Interval).

\begin{tabular}{cccc}
\hline SNP & OR $(95 \% \mathrm{CI})$ & P value & GENE \\
\hline rs4402960 & $1.15(1-1.33)$ & 0.05 & IGF2BP2 \\
rs1049817 & $1.15(1-1.34)$ & 0.06 & GCKR \\
rs16857648 & $1.18(0.99-1.39)$ & 0.07 & CACNA1E \\
rs7961581 & $1.14(0.99-1.32)$ & 0.07 & TSPAN8 \\
rs8122476 & $1.16(0.98-1.36)$ & 0.08 & HNF4A \\
rs6547626 & $1.13(0.97-1.31)$ & 0.11 & GCKR \\
rs12053195 & $1.18(0.96-1.45)$ & 0.12 & NEUROD1 \\
rs7756992 & $1.12(0.97-1.3)$ & 0.12 & CDKAL1 \\
rs4607103 & $1.12(0.97-1.3)$ & 0.13 & ADAMTS9 \\
rs6076472 & $1.12(0.97-1.29)$ & 0.13 & TRIB3 \\
rs2391489 & $1.11(0.97-1.27)$ & 0.13 & JAZF1 \\
rs12490804 & $1.12(0.97-1.29)$ & 0.14 & ADAMTS9 \\
rs1111875 & $1.11(0.97-1.28)$ & 0.14 & HHEX \\
\hline
\end{tabular}




\section{Continued}

\begin{tabular}{|c|c|c|c|}
\hline rs1873555 & $1.11(0.96-1.28)$ & 0.15 & THADA \\
\hline rs1801282 & $1.19(0.93-1.51)$ & 0.16 & PPARG \\
\hline rs10521304 & $1.1(0.96-1.27)$ & 0.16 & FTO \\
\hline rs8731 & $1.12(0.95-1.32)$ & 0.16 & GCKR \\
\hline rs7223387 & $1.11(0.96-1.29)$ & 0.17 & HNF1B \\
\hline rs17236708 & $1.1(0.96-1.25)$ & 0.18 & FTO \\
\hline rs11710969 & $1.12(0.95-1.31)$ & 0.18 & PPARG \\
\hline rs920779 & $1.14(0.94-1.39)$ & 0.19 & ADAMTS9 \\
\hline rs4444493 & $1.13(0.94-1.37)$ & 0.20 & KLF11 \\
\hline $\mathrm{rs} 2384628$ & $1.09(0.95-1.25)$ & 0.20 & GCKR \\
\hline rs13266634 & $1.1(0.95-1.28)$ & 0.22 & SLC30A8 \\
\hline rs2184945 & $1.09(0.95-1.25)$ & 0.23 & CACNA1E \\
\hline rs4675095 & $1.15(0.92-1.44)$ & 0.23 & IRS1 \\
\hline rs6115830 & $1.08(0.95-1.24)$ & 0.23 & TRIB3 \\
\hline rs 175338 & $1.11(0.94-1.3)$ & 0.24 & CACNA1E \\
\hline rs11024295 & $1.09(0.95-1.25)$ & 0.24 & ABCC 8 \\
\hline rs3905011 & $1.08(0.95-1.24)$ & 0.25 & CACNA1E \\
\hline rs10938397 & $1.08(0.94-1.24)$ & 0.25 & GNPDA2 \\
\hline rs10797728 & $1.09(0.93-1.28)$ & 0.27 & CACNA1E \\
\hline rs6432052 & $1.1(0.93-1.29)$ & 0.29 & KLF11 \\
\hline rs7923837 & $1.08(0.94-1.24)$ & 0.29 & HHEX \\
\hline $\mathrm{rs} 1477092$ & $1.08(0.94-1.25)$ & 0.29 & FTO \\
\hline rs708258 & $1.07(0.94-1.23)$ & 0.31 & FTO \\
\hline rs6781019 & $1.07(0.94-1.24)$ & 0.31 & IGF2BP2 \\
\hline rs3753737 & $1.08(0.93-1.25)$ & 0.32 & CACNA1E \\
\hline rs2158254 & $1.07(0.94-1.22)$ & 0.32 & HNF1B \\
\hline rs9493119 & $1.15(0.88-1.5)$ & 0.32 & ENPP1 \\
\hline rs4669522 & $1.08(0.92-1.28)$ & 0.35 & KLF11 \\
\hline rs7635505 & $1.07(0.93-1.23)$ & 0.35 & ADAMTS9 \\
\hline rs 12071300 & $1.08(0.91-1.29)$ & 0.36 & CACNA1E \\
\hline rs882019 & $1.06(0.93-1.22)$ & 0.36 & GCK \\
\hline rs1036920 & $1.07(0.92-1.25)$ & 0.36 & ADAMTS9 \\
\hline rs7578597 & $1.11(0.89-1.37)$ & 0.37 & THADA \\
\hline rs2868094 & $1.07(0.92-1.23)$ & 0.38 & HNF4A \\
\hline rs560887 & $1.07(0.92-1.24)$ & 0.39 & G6PC2 \\
\hline rs13099634 & $1.07(0.91-1.27)$ & 0.42 & PPARG \\
\hline rs483109 & $1.06(0.92-1.22)$ & 0.42 & G6PC2 \\
\hline rs4652679 & $1.06(0.91-1.24)$ & 0.45 & CACNA1E \\
\hline
\end{tabular}




\section{Continued}

\begin{tabular}{|c|c|c|c|}
\hline rs1476891 & $1.06(0.92-1.22)$ & 0.45 & GCK \\
\hline rs6708660 & $1.06(0.92-1.21)$ & 0.45 & THADA \\
\hline rs11989843 & $1.06(0.89-1.27)$ & 0.49 & SLC30A8 \\
\hline rs2708104 & $1.05(0.91-1.21)$ & 0.51 & HNF1A \\
\hline rs11897732 & $1.05(0.91-1.2)$ & 0.52 & THADA \\
\hline rs11523890 & $1.05(0.9-1.22)$ & 0.53 & MTNR1B \\
\hline rs10495899 & $1.05(0.88-1.26)$ & 0.56 & THADA \\
\hline rs6721191 & $1.04(0.91-1.19)$ & 0.57 & KLF11 \\
\hline rs10830963 & $1.04(0.9-1.22)$ & 0.58 & MTNR1B \\
\hline rs4607517 & $1.05(0.88-1.24)$ & 0.58 & GCK \\
\hline rs1303722 & $1.04(0.9-1.2)$ & 0.58 & GCK \\
\hline rs4148638 & $1.04(0.89-1.22)$ & 0.59 & ABCC 8 \\
\hline rs6065726 & $1.04(0.89-1.23)$ & 0.60 & HNF4A \\
\hline rs6763887 & $1.04(0.9-1.21)$ & 0.61 & IGF2BP2 \\
\hline rs9581927 & $1.04(0.9-1.19)$ & 0.61 & PDX1 \\
\hline rs6130595 & $1.04(0.89-1.22)$ & 0.61 & HNF4A \\
\hline rs689266 & $1.04(0.9-1.21)$ & 0.61 & CEL \\
\hline rs7310409 & $1.03(0.9-1.19)$ & 0.63 & HNF1A \\
\hline rs679931 & $1.04(0.9-1.2)$ & 0.63 & CACNA1E \\
\hline rs7623286 & $1.03(0.9-1.18)$ & 0.66 & ADAMTS9 \\
\hline rs6939185 & $1.03(0.9-1.19)$ & 0.67 & ENPP1 \\
\hline rs10774580 & $1.03(0.9-1.18)$ & 0.68 & HNF1A \\
\hline rs6548238 & $1.04(0.88-1.22)$ & 0.69 & TMEM18 \\
\hline rs6139007 & $1.03(0.89-1.2)$ & 0.70 & TRIB3 \\
\hline rs4148625 & $1.03(0.89-1.18)$ & 0.71 & ABCC 8 \\
\hline rs7102746 & $1.03(0.9-1.17)$ & 0.71 & MTNR1B \\
\hline rs1801262 & $1.03(0.89-1.18)$ & 0.72 & NEUROD1 \\
\hline rs630288 & $1.03(0.88-1.19)$ & 0.73 & CEL \\
\hline rs11768607 & $1.02(0.89-1.18)$ & 0.75 & GCK \\
\hline rs10766406 & $1.02(0.89-1.17)$ & 0.76 & ABCC 8 \\
\hline rs6717980 & $1.02(0.88-1.18)$ & 0.76 & GCKR \\
\hline rs1801278 & $1.04(0.8-1.34)$ & 0.78 & IRS1 \\
\hline rs9923233 & $1.02(0.89-1.17)$ & 0.78 & FTO \\
\hline rs2466296 & $1.02(0.87-1.2)$ & 0.79 & SLC30A8 \\
\hline rs4656253 & $1.04(0.77-1.4)$ & 0.80 & PEA15 \\
\hline rs9933107 & $1.02(0.88-1.18)$ & 0.80 & FTO \\
\hline rs8075185 & $1.02(0.89-1.16)$ & 0.81 & HNF1B \\
\hline rs1169302 & $1.02(0.89-1.16)$ & 0.83 & HNF1A \\
\hline
\end{tabular}




\section{Continued}

\begin{tabular}{|c|c|c|c|}
\hline rs10923931 & $1.03(0.8-1.32)$ & 0.83 & NOTCH2 \\
\hline rs853770 & $1.01(0.88-1.17)$ & 0.87 & G6PC2 \\
\hline rs6031596 & $1.01(0.88-1.16)$ & 0.87 & HNF4A \\
\hline rs4897549 & $1.01(0.87-1.18)$ & 0.87 & ENPP1 \\
\hline rs 17832252 & $1.01(0.84-1.22)$ & 0.88 & GCK \\
\hline rs1169286 & $1.01(0.88-1.16)$ & 0.89 & HNF1A \\
\hline rs858340 & $1.01(0.87-1.17)$ & 0.89 & ENPP1 \\
\hline rs 12475700 & $1.01(0.88-1.16)$ & 0.89 & G6PC2 \\
\hline rs1169303 & $1.01(0.88-1.15)$ & 0.90 & HNF1A \\
\hline rs558994 & $1.01(0.87-1.17)$ & 0.90 & CACNA1E \\
\hline rs6544647 & $1.01(0.88-1.15)$ & 0.91 & THADA \\
\hline rs7632 & $1.01(0.88-1.15)$ & 0.91 & KLF11 \\
\hline rs 17024486 & $1.03(0.68-1.55)$ & 0.91 & NOTCH2 \\
\hline rs7265169 & $1.01(0.81-1.26)$ & 0.92 & TRIB3 \\
\hline rs3110648 & $1.01(0.85-1.2)$ & 0.92 & HNF1B \\
\hline rs7589033 & $1.01(0.87-1.16)$ & 0.93 & THADA \\
\hline rs190 & $1.01(0.88-1.16)$ & 0.93 & JAZF1 \\
\hline rs 10505310 & $1.01(0.85-1.19)$ & 0.95 & SLC30A8 \\
\hline rs9666752 & $1(0.88-1.15)$ & 0.95 & MTNR1B \\
\hline rs709149 & $1(0.88-1.15)$ & 0.95 & PPARG \\
\hline rs6445425 & $1(0.88-1.15)$ & 0.95 & ADAMTS9 \\
\hline rs2253388 & $1(0.87-1.16)$ & 0.96 & CACNA1E \\
\hline rs8048396 & $1(0.88-1.15)$ & 0.98 & FTO \\
\hline
\end{tabular}

There are two main physiological outputs of the model:

1) derivative control (units: $\left[\mathrm{pmol} \cdot \mathrm{m}^{-2} \mathrm{BSA}\right] \cdot\left[\mathrm{mmol} \cdot \mathrm{l}^{-1} \cdot \mathrm{min}^{-1}\right]^{-1}$ ): it is the amount of insulin secreted in response to a rate of glucose increase of $1 \mathrm{mmol} / \mathrm{l}$ per min which lasts for 1 minute;

2) stimulus-response curve linking glucose concentration ( $x$ axis) to insulin secretion rate ( $y$ axis): as explained above, it is the sum of BSR and PSR. With the purpose of avoiding artifactual increases in the power of statistical analyses, we used the stimulus-response curve at the pre-determined glucose concentrations of $5.5,8.0,11.0,15.0$ and $20.0 \mathrm{mmol} / \mathrm{l}$. 